\title{
Erratum to: The Role of Systemic Risk Factors in Diabetic Retinopathy
}

\author{
Elizabeth Atchison $^{1} \cdot$ Andrew Barkmeier ${ }^{1}$
}

Published online: 10 August 2017

(C) Springer Science+Business Media, LLC 2017

Erratum to: Curr Ophthalmol Rep (2016) 4:84-89

https://doi.org/10.1007/s40135-016-0098-8

The article The Role of Systemic Risk Factors in Diabetic Retinopathy, written by Elizabeth Atchison and Andrew Barkmeier, was originally published Online First without open access. After publication in volume 4, issue 2, page 84-89 the author decided to opt for Open Choice and to make the article an open access publication. Therefore, the copyright of the article has been changed to $(\subset)$ The Author(s) 2016 and the article is forthwith distributed under the terms of the Creative Commons Attribution 4.0 International License (http://creativecommons.org/licenses/by/4.0/), which permits use, duplication, adaptation, distribution and reproduction in any medium or format, as long as you give appropriate credit to the original author(s) and the source, provide a link to the Creative Commons license, and indicate if changes were made.

The online version of the original article can be found at https://doi.org/ 10.1007/s40135-016-0098-8

Elizabeth Atchison

atchison.elizabeth@mayo.edu

Andrew Barkmeier

barkmeier.andrew@mayo.edu

1 Mayo Clinic, 200 1st St SW, Rochester, MN 55902, USA 